\title{
A CONSTITUIÇÃO DO MUNDO E DE SI-PRÓPRIO NO ENLACE EXISTENCIAL MÃE-BEBÊ
}

\author{
The Constitution of the World and the One's Own Body in the Mother-Baby Existential Enlace
}

La Constitucíon del Mundo y del Si-Mismo en la Unión Existencial de la Madre y el bebé

FÁBIO LUIZ SOCREPPA DA FONSECA

\begin{abstract}
Resumo: O presente escrito trata de uma fenomenologia acerca da constituição de mundo e de si-próprio a partir do corpo-infans. A existência humana demanda um mundo. Sua formação se dá em meio às vivências de sociabilidade que possibilitam a apropriação dos sentidos na corporeidade. Essa constituição do horizonte cultural tem como alicerce o enlace existencial mãe-bebê, cuja relação é abertura para uma possibilidade de mundo. O papel existencial da mãe tem como fundo a sociabilidade vivida; a mulher ao se tornar mãe apropria-se dos modos de maternagem existentes em sua sociabilidade e os seus cuidados para com o corpo do infans são o fundamento para a constituição do mundo do infans. Por fim, entende-se que a mãe e o bebê constituem-se em meio aos seus papeis existenciais vividos e que o mundo formado pelo infans sempre esteja ligado às suas vivências com a mãe.
\end{abstract}

Palavras-chave: Fenomenologia das idades da vida; Corpo-infans; Constituição de mundo; Maternagem; Enlace existencial mãe-bebê.

\begin{abstract}
This paper is about the phenomenology of the world's constitution from the body-infans. Human living-experience claims a world. Its formation occur in the middle of the social-experiences that makes the embodied appropriation of meaning possible. This constitution of the cultural horizon has, as its foundation, the mother-baby's existential enlace, whose relation is the opening for a possible world. The existential role of the mother has the living sociability as its background; the woman who became a mother takes possession of the existing mothering styles in her sociability and her caring for the body-infans becomes the basis for the constitution of the infans's world. Lastly, It is known that the mother and the baby are constituted by living their existential role, and that the world constituted by the infans is always connected by its living-experiences with the mother.

Keywords: Phenomenology of the ages of live; Body-infans; World constitution; Mothering; Mother-baby's existential enlace.

Resumen: Este escrito es una fenomenología sobre la constitución del mundo y del si-mismo a partir del cuerpo-infans. La existencia humana exige un mundo. Su formación se lleva a cabo en medio de las experiencias de sociabilidad que permiten la apropiación de los sentidos en la corporalidad. Esta constitución del horizonte cultural tiene como fundamento la unión existencial madre-hijo cuya relación es la apertura para una posibilidad de mundo. El papel existencial de la madre es como contexto para la sociabilidad vivida; cuando la mujer se convierte en madre, ella se apropia de los modos existentes del cuidado infantil en suya sociabilidad y suyos cuidados para el cuerpo del infans son la base para la constitución del mundo-infans. Por último, se lo entiende que la madre y el bebé están en medio de sus funciones existenciales experimentadas y el mundo formado por el infans es siempre conectado a sus experiencias con la madre.

Palabras-clave: Fenomenologia de las idades de la vida; Cuerpo-infans; Constitución del mundo; Cuidados maternales; Unión existencial de la madre y el bebé.
\end{abstract}

\section{Introdução: a constituição de um mundo possível}

As pessoas convivem no mundo, o percebem e comungam sua fonte de vida. Seu viver é inocente ao reconhecimento das espessuras presentes no cotidiano, como as crenças, o idioma, os hábitos, os nomes dos objetos no mundo são tomados como uma coincidência histórica ou mesmo como algo natural. O mundo constituído não é questionado quanto a sua natureza ou pela importância do seu papel na formação identitária.
Para a fenomenologia a constituição de mundo ${ }^{1}$ principia-se na incursão da pessoa na comunidade a qual ele nasce e esse movimento segue perpetuamente durante toda a existência do sujeito. Tem como fundação o mundo da vida, entendido aqui como nascente apriorística

\footnotetext{
Cf. Garc \& Olaso. (1978). Constituição trata-se de um vocábulo que oscila entre a fundar ou ordenar dados. Em uma perspectiva kantiana constituir refere-se a ação das categorias apriorísticas da consciência que formam a intuição sobre o objeto do conhecimento, não tocando o objeto concreto. Já em Husserl o problema da constituição encontra-se sempre presente, em especial no segundo livro de IDEIAS, o filósofo dedica grande parte a "investigações fenomenológicas para a constituição", tendo em vista a questão da significação estabelecida do objeto na consciência.
} 
de todos os mundos possíveis (Zilles, 2008), e de sua ligação fundamental à sensibilidade corpórea. Perceber o mundo significa apreendê-lo por meio da materialidade dos sentidos; a isso implica dizer que todo o relacionamento com o outro, sejam pessoas, coisas, abstrações ou objetos imaginados, perpassam a estrutura perceptiva para compor o mundo pessoal do ser (Le Breton, 2016). A fenomenologia afasta-se assim das posições idealistas da consciência constituinte ${ }^{2}$ e trata da correlação existente entre a percepção e a materialidade do mundo para a constituição do real (Capalbo, 2008).

A existência humana consiste na condição de ser corpo situado em um mundo, realidade sempre presente que integra a pessoa aos diferentes lugares que ocupa. O corpo está sempre relacionado ao mundo, sua sensibilidade se encrava nele de tal modo que marca o percebido como uma referência própria. $\mathrm{O}$ mundo surge no entrelaçamento ${ }^{3}$ constituído entre sua imanência e o modo particular como essa é apreendida na percepção.

Os elementos que circundam a percepção são acolhidos na corporeidade como ecos que reverberam o vivido. A gestualidade alcança os objetos no entorno intencionalmente, um modo particular de iluminar o percebido segundo uma perspectiva que se conforma à sua maneira de exploração do mundo (Nobrega, 2010). O conhecimento nascido desse contato advém da intimidade existente nessa relação, uma apropriação de aspectos do real que inclui na percepção e nos gestos do corpo o sentido constituído no encontro (Ibidem).

O termo sentido é apresentado aqui como orientação existencial fundada pelo sujeito em meio as suas vivências. A formação de sentido possui instâncias pré-linguísticas e linguísticas que partem da materialidade dos sentidos corpóreos para conjunção complexa do sentido como possibilidade existencial (Josgrilberg, 2015).

A ordenação dos sentidos apropriados compõe o mundo horizonte do sujeito, organizando de modo profundo como a percepção apreende o entorno. A constituição do mundo se dá na educação dos sentidos corpóreos em consonância aos elementos de mundo vividos por essa comunidade linguística; os sentires corpóreos rumam à consonância dos modos de nomeação desses elementos de mundo dada à própria vivência com eles. Assim, o perfume de cerejeira é ligado ao ser da sua flor ou o como as cores são dotadas de seus nomes ou que os contornos do mundo são nutridos de sua sensualidade (Le Breton, 2016). Os destaques entre o visível e o invisível formam normas que são intuídas em meio à comunidade, o pró-

\footnotetext{
2 Cf. Landes. (2013). Noção atribuída às filosofias idealistas e transcendentalistas centradas em doar sentido ao mundo. Para o autor a análise reflexiva voltaria às estruturas da consciência, enquanto a análise fenomenológica do corpo próprio e da percepção revela uma relação mais profunda com os objetos.

3 Cf: Josgrilberg. (2016). O entrelaçamento é uma profunda compreensão filosófica, os gregos a tratavam como symploke, uma coisa que existe na outra. Na fenomenologia husserliana esse termo é reencontrado como Intentionales ineinander.
}

prio sentir o meio é nutrido consorte aos modos como se dá a sociabilidade vivida.

Conviver com os outros tem um papel fundamental na organização da percepção corpórea. Os sentidos incluídos na corporeidade não são idênticos aos dos demais viventes de sua comunidade, mas uma perspectiva assumida a partir das vivências com os outros (Le Breton, 2016). O mundo constituído, ao deter em seu horizonte, a valoração dos elementos físicos e abstratos do meio, também educa o ser sobre quem ele é. $\mathrm{O}$ ato de perceber já é compreensão da realidade vivida.

A pessoa constitui-se juntamente com o mundo percebido. A corporeidade é sempre um direcionamento ao seu horizonte, o qual aplaca suas carências existenciais, a intencionalidade corpórea revela vontades segundo os sentidos elegidos no curso da vida, dentro das possibilidades simbólicas do mundo vivido pelo sujeito. $\mathrm{O}$ desenvolvimento da pessoa no mundo se dá pelos campos em que essa encontra sentido de vida; vivenciar esses diferentes lugares do mundo abre possibilidades de educar a percepção a outros possíveis. As pessoas se formam e assumem particularidades de cada experiência que a marcou em um nível profundo, o ser se transforma em suas vivências e se revela a si mesmo para si e para o mundo vivido (Merleau-Ponty, 2006a)

Constituir um mundo, incorporar seus elementos segundo uma organização própria, significa também apropriar-se de si-mesmo. O contorno dos gestos denota a intencionalidade consonante aos sentidos presentes no mundo, pois essas significações existem como orientação presente no horizonte vivido pelo sujeito. Revela-se um estilo de ser junto ao mundo com que a pessoa se entrelaça. O corpo alinhava seus modos de conhecer, seus sentidos corpóreos, segundo os modos presentes em seu mundo vivido; toda a expressão de sua gestualidade encarna esses sentidos vividos e constrói a identidade da pessoa.

Trata-se de uma atividade perpétua a constituição de si-próprio, uma continuidade que situa o ser dentro de certos campos presentes dentro de uma sociedade. Nesses lugares o sujeito se abre a novas possibilidades de ser e tem-se proposto ai um jogo existencial cujo objetivo é a instituição na corporeidade de modos mais refinados de se perceber certos aspectos do mundo. O sujeito conhece a si mesmo em meio aos atos que empreende no mundo e no gesto solidário de se reconhecer nos atos daqueles em quem ampara esse estilo ${ }^{4}$, como pelo alcance dos resultados intencionados a partir desse estilo. Esses jogos existenciais são aqui chamados de jogos de si-mesmo com os outros (Josgrilberg, 2016).

A constituição do mundo e de si próprio se dá infindavelmente no curso da vida e seu princípio encontra-se situado desde as primeiras vivências de mundo. A feno-

\footnotetext{
Cf. Rocha, (1997). Merleau-Ponty explica que Husserl introduziu a noção de estilo para traduzir os modos como se dá a relação com o mundo, o meio pelo qual ocorre a tradução expressiva da compreensão vivida do mundo.
} 
menologia das idades da vida é apresentada por Josgrilberg (2015) como possibilidade para se aprofundar os saberes acerca da corporeidade em diferentes épocas do existir. O corpo transforma-se ao longo da existência e os modos como ele é vivido depende das possibilidades existentes em determinada idade da vida. Cada uma dessas fases do existir é demarcada por aspectos existenciais que lhes são próprios e essas possibilidades deixam traços nas fases de vida subsequentes.

A primeira possibilidade de corpórea é vivida pelo infans, uma fase de vida em que a formação do corpo realiza-se principalmente a partir de formações passivas. O infans é um corpo não falante. As intencionalidades corpóreas do infans são inicialmente difusas e somente pelos cuidados ofertados por outrem que suas urgências corpóreas podem ser acalentadas. A absorção desses cuidados não ocorre sem a inclusão desses no modo de existir do infans, um mundo surge entre ele e aqueles que cuidam de seu corpo.

A mãe é a figura central na vivência do infans. Entendemos a mãe como um papel existencial de cuidado e formação das pessoas em uma dada sociedade, não pretendendo tornar esse um papel exclusivo a uma só pessoa (seja mulher ou homem), pois coexistem muitas possibilidades de formação nas diversas comunidades existentes (e mesmo dentro de uma mesma comunidade).

Esse texto concentra seus esforços no papel da mãe biológica em sua relação com o bebê e da sua participação por meio dos atos de maternagem para a constituição do mundo e do si-próprio do bebê. Sua relação para com o seu corpo tem início na gestação e os ecos de seus cuidados são fundantes da mundicidade do infans. A maternagem é a abertura para a sociabilidade vivida, para os contornos dos movimentos e para a linguagem. Dada essa importância para a constituição do mundo, estabelece-se uma hermenêutica da formação cultural e do papel existencial da mãe a fim de se ampliar os saberes acerca de como se dá a passagem da cultura. Em um segundo momento se analisa a relação constituída entre o corpo-infans e a mãe como visada ao fenômeno da constituição do mundo e de si próprio.

\section{O fenômeno da maternagem e a cultura.}

Nascer em uma forma de sociabilidade é participar de sua constituição. Isso significa ao se viver essa forma de cultura assume-se seu estilo, um fundo estruturante de significações que são apropriadas na corporeidade e que lhe possibilita comunicar-se com os outros. A nascente desse processo de constituição de mundo consagra-se na relação mãe-bebê, ela é a pessoa que media o adentrar do corpo-infans por meio dos cuidados presentes na maternagem.

A presença da mulher é inalienável para a gestação de outrem, uma vez que essa possibilidade existencial só pode ser comportada pelo seu corpo. Cada pessoa já pertenceu à corporeidade daquela que o gestou, sua carne já fez parte de sua carne, assim como da história vivida por ela. A figura da mãe é uma constante em muitas culturas, mas não em todas; existe àquelas cuja criança é filha da própria comunidade. Do mesmo modo os cuidados da maternagem podem variar frente a vastidão de estilos presentes nas culturas, pois o corpo-infans demanda tal atenção. Assim, o papel do que chamamos aqui de mãe pode variar dentre aquelas pessoas que são referências centrais para as crianças em uma dada forma de sociabilidade.

A maternagem, enquanto resumo das habitualidades de cuidado de uma criança, exerce um papel fundamental na criação de uma pessoa em uma sociabilidade. Sua própria constituição deriva do estilo de ser presente nessa cultura e expressa o como é compreendida a formação humana ali vivida. Contudo, de que modo a maternagem agrega essa possibilidade formadora do ser e como isso se apresenta nos atos da mãe no cuidado da criança? Essa sessão se dedica a essas questões.

\section{Cultura e maternagem}

A ocupação humana do espaço é uma apropriação particular realizada por uma comunidade dotada de habitualidades que conformam a paisagem ao culturalmente formado. A compreensão do que compõe o mundo constituído está além do conhecimento isolado acerca de sua arquitetura, tecnologia ou crenças pertencentes a uma sociedade, essa formação depende da história constituída por esse povo. Inclui os avanços conquistados, sem destituí-los de sua condição co-criada na cultura (Le Breton, 2016).

Todas as culturas comungam o mundo da vida e de seu incomensurável poder de acolher mundos possíveis em seu corpo (Husserl, 2008). Ao longo da paisagem e junto com as demais formas de vida, as populações humanas estruturaram seu modo de ser e viver. A abertura ao mundo revela às pessoas sentidos para a sua existência. Elementos da natureza se destacam como nutrientes por seu sabor, ou ainda por oferecer deleite aos sentidos do corpo. A vivência com o outro, aberta ao mundo, encontra inúmeros possíveis a ser sedimentados em linguagem dado o seu valor no tempo vivido. Uma deformação coerente do natural lhe direciona a ser um objeto cultural, tanto por sua transformação concreta em instrumento ocorrida pela mão humana, como pelo nome doado em situação (Rocha, 1997).

Estabelece-se uma sincronia entre os modos de vida vividos por uma comunidade e os sentidos que ela encontra no mundo. A linguagem ocupa ai um papel primordial, pois (Merleau-Ponty, 2006a, p. 266) “[...] ela é uma manifestação, uma revelação do ser intimo e do elo psíquico que nos une ao mundo e aos nossos semelhantes [...]", e aquilo que nela rege sedimentado funda certa ver- 
dade assumida acerca do objeto em seu tempo histórico. A isso não cabe o entendimento de que o nome do objeto o liga a intencionalidade de seu uso, mas que a presença de seu nome como valor de uso social mostra sua importância a uma comunidade. Os sentidos sincrônicos a um determinado tempo histórico, seja como objeto concreto ou como subjetivo (tal como as habitualidades sociais), existem por seu poder de expressividade entre os membros dessa comunidade (Merleau-Ponty, 1991).

A passagem do tempo faz emergir dentre o curso das sucessivas sincronias a percepção da diacronia. Na história de uma sociedade inúmeros acasos levam formas comunicativas a se manter, mudar seu sentido expressivo ou mesmo cair em desuso. O mesmo pode ser dito em relação aos hábitos, crenças e aos problemas sociais presentes em determinados momentos históricos (Merleau-Ponty, 1991). As intencionalidades constituídas como sentidos para certos aspectos da realidade servem como forro àqueles presentes em outros períodos, a sociabilidade se mantem em movimento em meio às pessoas que são concomitantemente fruto e produtoras dessa cultura (Rocha, 1997). Um forro de verdades é ambiguamente assumido, se em um momento é por essas significações do real que as pessoas se direcionam e sua história as atinge por certa sinergia histórica, em outro momento essas significações são insuficientes e as pessoas demandam a criação de novas formas de se expressar (Merleau-Ponty, 2006a).

A estruturação comum de sentidos rege a consolidação das percepções de mundo em uma sociedade, isso quer dizer que as intencionalidades vividas pelos ancestrais de uma comunidade ecoam nos tempos atuais, que determinados dilemas e mistérios que tomavam certa época ainda se encontram no presente. Pertencer a uma cultura significa ser incluído, com os demais nascentes dessa sociabilidade, a uma intencionalidade histórica. É assumir certo estilo de ser comungado por todos que participam de sua confecção e cuja realização ocorre no curso da vida de todas as pessoas que pertencem a essa sociabilidade (Rocha, 1997).

A conjuntura dos modos de ser dentro da sociedade compõe um estilo geral vivido, os papeis sociais e os modos de vivê-los, assim como a organização social é fruto da história. O desenvolvimento da comunidade conduz a maior complexidade de suas estruturações sociais e papeis novos são demandados, assim como novas formas de cuidado são criadas. Novos estilos se formam e expressam as novas demandas existentes na comunidade, modos particulares de viver certos papéis dentro da sociedade se constituem e expressam os contornos próprios dentro dessa forma de sociabilidade ${ }^{5}$.

\footnotetext{
5 Cf: Le Breton. (2016, p. 26). Não é o real que os homens percebem, mas imediatamente um mundo de significações” Le Breton expõe, junto a Merleau-Ponty que a percepção é uma potência ativa do corpo e essa possibilidade corpórea se organiza com a inclusão do modo como se percebe a realidade por uma determinada cultura.
}

A maternagem compõe a modalidade do estilo de ser que se dedica aos cuidados formadores de mundo. Esses são ecos das preocupações concernentes à existência presentes na história da sociabilidade que os produz. A cultura se encontra em constante desenvolvimento em virtude das novas distinções realizadas na vida cotidiana. A ampliação da reflexão e da linguagem acerca dos cuidados necessários para o desenvolvimento das crianças se encontram no mesmo curso. As pessoas que acolhem as crianças com as atitudes de maternagem já a viveram de algum modo, a perspectiva de cuidado se aprofunda entre o já vivido e os avanços sociais existentes nessa comunidade.

A proximidade, o acalento das urgências corpóreas, assim como a vivência de jogos, afetos e diálogos constituem a abertura do ser-em-formação às suas possibilidades de ser e a sua vinculação dentro dessa forma de sociabilidade. Os cuidados vividos já oferecem aos seus sentidos corpóreos o sentido existencial de cuidado, o estilo de ser vivido em sua cultura. A maternagem é a porta de entrada a participação na mesma.

\section{A mãe enquanto papel existencial e enquanto pessoa}

Embora existam pessoas que participem da responsabilidade de formação e exerçam práticas relativas à maternagem para a criança, identifica-se no papel existencial da mãe a centralidade a ação desses cuidados à criança. Essa possibilidade de ser no mundo ocidental é primordialmente assumida por quem mais se dedica à maternagem da criança, podendo esse papel existencial ser exercido por aquela que a gesta, por mães ou pais adotivos, assim como as famílias-social. Para os fins desse texto será analisada a posição de maternidade a partir da mãe biológica.

A mulher já carrega um mundo em constituição, a sua vida conjuga vivências formadoras desse mundo dotado de sabores, cheiros, cores e humores dados na sociabilidade vivida. Nesse horizonte apropriado a mulher vive a tarefa de ser si mesmo, assume os papeis e situa-se como sujeito e interprete da mundicidade vivida. Em meio as suas possibilidades, o corpo feminino carrega a potência existencial da gestação e muito embora não lhe seja dever o gestar alguém, esse é um poder de seu ser.

A vida humana começa no corpo de uma mulher. É fruto de sua carne e no percurso que segue da fecundação ao nascimento a mãe e o bebê habitam a mesma corporeidade. O corpo-grávido da mulher é a abertura da vida ao ser vindouro ao mundo, do mesmo modo, os cuidados vividos na maternagem são a entrada ao horizonte cultural. O modo de exercer a maternidade é uma extensão do estilo de ser apropriado no curso de vida da mulher e tal como outros papeis existenciais, esse sofre especial cobrança em relação ao como vivê-lo.

O modo de ser forma-se na reverberação dos sentidos vividos e sua expressividade entrega a síntese de quem é 
essa pessoa no mundo. Cada ser vivente de uma forma de sociabilidade carrega símbolos comuns à sua comunidade, tem encarnada sua linguagem e o entendimento sobre o funcionamento das estruturas de mundo ali constituídas (Rocha, 1997). Tanto os papeis sociais como o entendimento sobre os gêneros humanos, a divisão social da riqueza, a crença teológica, as diferentes tonalidades de pele, as demais espécies de animais, como o modo que se ocupa a paisagem são apropriações socialmente constituídas segundo uma valoração particular, realizadas em meio as vivências que tematizam esses sentidos de mundo. Papéis existenciais como mãe, pai, filho, amigo etc., são igualmente constituídos no curso da diacronia, mas sua assunção pessoal varia conforme esse sentido de ser é apropriado no curso de existir do sujeito.

A constituição do mundo pessoal tem como fundo o horizonte cultural comungado pelos membros de uma mesma comunidade, cuja outrassidade revela, entre a consonância e a dissonância de sentidos possíveis, as diferentes perspectivas existentes (Le Breton, 1997). Um jogo de papeis emerge nesses acordos e desacordos acerca do mundo, se por vezes uma pessoa encontra-se em concordância com outrem, haverá momentos em que estarão em desacordo. Junto aos outros o sujeito conhece a si próprio e o modo como ele se encontra situado em meio ao mundo em que vive. A apropriação de si é possível na ludicidade de se poder dispor de posições variadas diante da existência, ai o si mesmo entra em jogo e o reconhecimento de si advém da solidariedade ao perceber o outro também como sujeito no mundo (Josgrilberg, 2016, Merleau-Ponty, 2006b). Trata-se de uma situação co-criada.

A mãe vive a tensão entre as diferentes posições existentes de maternidade. Se por um lado a mulher torna-se mãe através da gestação de outrem, essa carrega consigo a vivencia de ser filha. Convive com outras mães e com o ideário social relativo aos modos de ser mãe. Sua maternidade é tocada pela experiência de outras pessoas, além das próprias. O si-mesmo da mãe forma-se com as demais pessoas, com os sentidos constituídos de maternagem desenvolvidos em seu mundo cultural. É uma síntese assumida como tarefa. A sedimentação desse si-mesmo encontra-se na própria história vivida e na outrassidade que oferta possibilidade de mimese ${ }^{6}$ dos posicionamentos existentes nesse mundo, para que então se deem como movimento próprio (Josgrilberg, 2016).

As memórias de ser filha e as narrativas relativas à maternagem são de suma importância a jovem mãe, contudo o tato direto com o bebê é a mais central das vivências formadoras desse papel existencial. A constituição

\footnotetext{
Cf: Josgrilberg. (2016). Trata-se de um conceito central na fenomenologia de Paul Ricouer. A mimese é criação. Intencionalidade operante relativa à alteridade. É a assunção de um movimento que se dá como narratividade encarnada existente no mundo e que se realiza a síntese daquilo que existe no meio em um sentido próprio. Pratica-se ai a mimese. Muito das ações humanas advém da possibilidade de narrar-se em um movimento próprio, ainda que a partir da ressonância do vivido de outras pessoas.
}

da vivência de maternidade se dá com a presença do bebê em seu mundo. O modo próprio de ser de uma mãe constitui-se na vivência desse papel existencial.

\section{A abertura de mundo a partir do enlace existencial mãe-bebê}

A constituição do mundo principia-se na experiência de ser do corpo infans e de seu enlace existencial à figura da mãe. Essa secção se dedica a investigar a experiência iniciada no corpo-gravido da mãe e das vivências de maternagem do infans até o surgimento da palavra.

A modalidade presente no corpo-gravido encontra a carne e vida da mulher-gestante como fonte da existência do ser-em-gestação, um processo que não se restringe ao biológico e que não existe sem ele. A mulher-gestante nutre e sente aquele que carrega em seu ventre. Compreende seu crescimento, inquietude, sono e alegria pela percepção dos novos sentidos que habitam o seu corpo. Este corpo-em-gestação encontra-se em crescimento. No início há uma relativa quietude, mas ao longo da gestação o bebê revela ser capaz de reagir ao mundo exterior à mãe, embora ainda não o habite.

Certamente é a mãe quem media as relações do mundo externo ao bebê, do mesmo modo que percebe seus movimentos. O ser-em-gestação reage muitas vezes ao humor afetivo vivido pela mãe, assim como a sua tranquilidade e estresse. Reage aos contatos com a barriga materna e o faz mesmo mediante a voz de algumas pessoas, mostrando relativa autonomia no ventre materno.

O seio do mundo que acomoda o bebê é um meio cultural e esse carrega modos de sociabilidade e linguagem no qual o bebê é inserido. No tanger cultural o corpo-gravido é aceito de diferentes formas, mas raramente escapa de ser tratado como um evento magnifico, frequentemente envolto de rituais sociais, habitualidades regionais e um profundo simbolismo. A mulher-gestante e aqueles que compõem seu entorno antecipam a presença do bebê no mundo, desenvolvem um modo de chamá-lo e acolhê-lo.

Este período é marcado pela fundação do espaço que esse virá a habitar no mundo. Em diferentes culturas são identificados preparos ritualísticos, cuidados destinados ao ser vindouro. Sua presença já marca o meio familiar antes do nascimento, uma vez que tais rituais constituem o anuncio de seu devir e a minúcia desses preparos é carregada de vestígios dos valores culturais que serão ungidos na criança. A mãe e as pessoas desse nicho familiar concebem assim a maternagem, modos para se cuidar do bebê, constituindo também traços do modo como se dará o educar dessa criança.

Este meio ancora socialmente a mãe na transitiva jornada de seu corpo-gravido e é continente ao fluir das vivências que culminam no evento existencial do nascimento. A mística desse evento evidencia uma modalidade de existência que já não é sustentável. O corpo urge por 
sucumbir ao desejo de ruptura que é o nascer. O corpo é tomado por uma demanda da natureza que irrompe a razão e ruma ao processo do parto, no qual o corpo-grávido dá a luz à nova modalidade de existir. A unicidade deriva na pessoa da mãe e do bebê.

Com o parto se dá o fim do corpo-gravido, mas não o enlace existencial constituído entre a mãe e o bebê $\hat{}^{7}$. A dependência do último aos cuidados externos é enorme, seus sentidos ainda difusos percebem um caos que é ordenado pela presença materna. A atenção exigida pelo bebê posiciona a mãe rumo ao sentido desse papel existencial, tanto o aleitamento como o cuidar das necessidades afetivas e fisiológicas, sedimentam as atitudes de maternagem necessárias à mãe. Do mesmo modo esses atos oferecem sentidos que são incorporados existencialmente pelo bebê (Le Breton, 2016).

A assunção desse papel existencial por parte da mãe é o forro da cultura para o bebê. A voz e os tratos maternos, o tempo dedicado ao bebê, tudo isso o embebe de signos culturais que são absorvidos tão rapidamente quanto isso lhe é possível. O corpo-infans é uma natureza em transição, o corpo-infante encontra-se em vias de constituição e os símbolos culturais são marcados passivamente nas suas vivências afetivas, cujo movimento de entrelaçar cultura e natureza que se realiza no corpo (Josgrilberg, 2015).

A vivência de entrelaçamento entre natureza e cultura também se dá na vivência materna de onde são desenvolvidas novas possibilidades de cuidado. A maternagem exige da mãe uma nova relação com a natureza, pois o corpo infante que derivou do seu próprio põe a mãe na direção da boa acuidade dos cuidados com o bebê, que não são naturais, mas tornam-se mais precisos conforme essa mãe é ensinada pelas pessoas de seu meio e principalmente pela vivência com o bebê. Assumir esse papel existencial, assim como qualquer outro, é por a si mesmo em um jogo em que os papeis até então constituídos em meio às vivências não são o suficiente para as novas possibilidades do real. No caso, a maternagem. A mãe passa a agir segundo uma nova ordem de atos que tem como função suprir a emergência do meio, os cuidados com o bebê.

O entrelaçar da cultura-natureza se encarna na mãe por meio desse jogo de cuidados em que o bebê se acalma e dá segurança aos gestos maternos. Do mesmo modo os gestos da mãe acalmam o bebê que também se beneficia da segurança dessa relação. Ainda que passivamente (de início) o bebê já é colocado nesse jogo existencial que se desenrolará por toda a vida, a constituição do si-mesmo com os outros (Josgrilberg, 2016).

Ainda que de modo tênue os sentidos percebidos pelo infante se tornam menos difusos conforme aumenta sua acuidade perceptiva mediante ao amadurecimento do corpo. Seu tônus muscular permite gestos mais precisos e o

\footnotetext{
Um ponto importante de ser explicitado é que esse enlace também se desenvolve em outras possibilidades de ser mãe, pois depende mais do envolvimento relacional entre a criança e aqueles que exercem a maternagem.
}

bebê demonstra mais claramente seus atos intencionais de curiosidade sobre o mundo a sua volta. A organização da sua percepção revela pessoas além da mãe. Embora ela seja seu eixo existencial, os outros além dela lhe são existentes, ainda que desconhecidos eles pertencem ao mundo infantil. Essas pessoas são o todo da extensão que lhe é familiar e que também cuidam dele. Como uma ciranda do existir apresentam signos culturais em seu entorno, expressam a sociabilidade vivida e desse modo ampliam o espaço percebido e as possibilidades de ser da criança (Merleau-Ponty, 2006a, 2006b).

O bebê absorve os afetos que lhe são dados. Corporeifica os tons de voz e a sensibilidade do tato. Encontra-se em processo de conhecer e organizar o mundo em seu entorno. Esse corpo infantil é um sensível em composição e demanda contato por meio do choro que exprime seus estados de humor ao mundo, este é um dos seus primeiros modos de comunicação e abertura a experiência da temporalidade (Merleau-Ponty, 2006b). Desde o nascimento a criança tem a possibilidade natural do chorar (Crystal, 2007; Le Breton, 2016). Esse choro é sempre resultado de uma necessidade emergencial que se dá pela fome, cólicas ou cansaço. A ação dos cuidadores da criança diante dessas urgências, seja pelo aleitamento materno ou pelo tato com tais necessidades, provê ao bebê a reconstituição de seu bem-estar.

O choro aparece como uma nova possibilidade expressiva à criança, atraindo os adultos a si, com o tempo vê-se esse estilo de ação utilizada em diferentes contextos, também por crianças mais velhas. As diferentes nuanças do choro infantil mostram sua potencia comunicativa, do mesmo modo que a criança percebe as variações de tonalidade de voz. Essa percepção é concebida no diálogo corpóreo da relação mãe-bebê, onde a mãe dá a sua voz como tonalidade do mundo (Crystal, 2007).

O choro que não se dá pelo desespero da fome ou desconforto, mas pela necessidade de contato (e isso é percebido também pela nuança e intensidade do choro) revela outras possibilidades comunicativas do choro, ainda que isso não seja plenamente consciente pelo bebê. $\mathrm{O}$ afago do choro pelo cuidado familiar repete-se constantemente. Nesse circulo o amparo cultivado tornar-se um símbolo vivido, que passa a ampliar o leque de possibilidades de choro a variações em que o choro não se dá pela angustia ou desespero, mas por reclamar de estar sozinho (Crystal, 2007; Merleau-Ponty, 2006b).

Chorar comunica as necessidades do bebê ao mundo (sendo esse centrado na mãe) e o amparo constitui o aprofundamento do enlace existencial entre a mãe e o bebê. Há a sedimentação do si-mesmo da mãe que encontra segurança no conforto do bebê e esse que ao vivenciar o acolhimento e bem-estar, aprofunda a possibilidade de ordenação de suas percepções e apropriações do mundo.

Possibilidades novas surgem conforme a estrutura biológica segue o amadurecimento do corpo infantil, seus sentidos organizados permitem uma expressão mais clara 
de suas intenções. Ao contrário dos primeiros meses em que a excitação se exprime pelo movimento agitado do corpo, o bebê é capaz de segurar ou afastar o que não o agrada, sua capacidade fônica o permite influir no meio por meio de interjeições, ainda que inicialmente ele nem mesmo ele perceba que o faça.

A fala materna é a porta de entrada da língua à criança, que dentro das suas possibilidades tem no tom e não nas palavras o sentido dos sons que existem no mundo. O corpo-infans é impactado pelos diferentes tons expressados pela mãe e por aqueles que estão presentes no entorno. Por ser mãe-centrado o bebê dedica sua percepção aos seus gestos e com isso os próprios contornos dos seus movimentos ganham sentido por levar a mãe a reagir de diferentes modos.

O bebê percebe com o tempo a potência de suas interjeições no meio, a relação de como os seus gestos impactam o meio e ainda que não seja capaz de se comunicar por meio das palavras, a criança repete sorrisos e determinados gestos a fim de receber determinado modo de atenção que percebe em seu entorno. A criança inclui em seus movimentos aquilo que percebe como significativo no comportamento de outrem (Crystal, 2007).

Nos gestos de se derrubar brinquedos a criança vive o espanto do distanciamento rápido do objeto, mas também a reação da mãe e das pessoas em seu entorno. As pessoas rapidamente se aproximam e a criança espanta-se com a alteração do meio. Se determinados gestos se iniciam ao acaso, eles ganham se enchem de sentido ao serem acolhidos na corporeidade da criança. No jogo de se bater a bola no chão o infans é encantado pelo movimento da bola e passar a buscar os mesmos resultados com a bola que o adulto obteve (Merleau-Ponty, 2006b). A ação do adulto ecoa nos gestos da criança. Do mesmo modo na dança a criança ao agitar o próprio corpo diante da música, afeta a corporeidade alheia por comoção. A mãe e os outros presentes se comovem por sua ação e isso fortalece o sentido desse movimento como modo de contato com as pessoas.

No caminho de exploração e construção do mundo infantil pelo bebê, a cultura exerce um papel fundamental. Embora a mãe seja a principal mediação da criança com o mundo, o infans se direciona aos objetos, animais, lugares e as demais pessoas que participam de seu cuidado, incluindo-os em seu mundo vivido. A cultura a qual todas essas pessoas pertencem marca a estruturação do corpo do bebê enquanto instalação no mundo por meio da língua, hábitos de sociabilidade, história e objetos sociais disponibilizados. O bebê pertence ao meio cultural do qual se apropria. A relação de afeto da criança com os outros em sua cultura sedimenta os estilos linguísticos que se estabelecem a mimese do ritmo da língua que as pessoas falam em seu entorno, apesar de ainda não haver ali frases ou palavras, existe o sentido da expressividade comungada entre as pessoas (Josgrilberg, 2016; Rocha, 1997).
O amadurecimento do corpo infantil amplia sua percepção de mundo conforme absorve e sedimenta as suas vivências. Enche-se de sentidos que estão além daqueles apreendidos por seu tato, audição, paladar e visão, preenche-se também por aquilo que existe no interstício deles e no resumo da expressão dos gestos de outrem que desaguam na relação de afetação para com ele (Le Breton, 2016). Os objetos são apropriados conforme o mundo constituído no entorno. A perspectiva assumida das relações com os outros e também o modo de vivê-las, seu sentido, é apreendido no corpo segundo a propagação das significações existentes no meio social. Funda-se uma verdade de mundo vivida junto aos outros.

Todas as vivências com a mãe e a intimidade de seus cuidados a tornam o fundamento do mundo. Isso é um algo vivido, anterior a qualquer razão da criança. As demais pessoas e elementos do real apresentados pela mãe são vividos e assim constituem essas verdades de mundo. O mundo constituído é fonte dos sentidos experimentados, são verdades vividas com os outros e que se revelam nas mais diferentes situações (Merleau-Ponty, 2006a). Esse fundo de verdades é o próprio espírito da cultura e da apropriação de mundo vivida.

As primeiras palavras da criança são consequência da sua disponibilidade corpórea que é o conjunto de sua estruturação bio-simbólica constituída em sua relação no mundo, que tem na linguagem a nata das relações comunicativas (Le Breton, 2016). É pela expressão dos gestos físicos e verbais da mãe e dos outros que o bebê se encanta pela potência expressiva da fala, pela relação entre os outros e por sua própria necessidade de se expressar e pertencer. Conforme Josgrilberg (2015, p. 24) “... a linguagem não é apenas um desenvolvimento do corpo ou do espírito: a linguagem só opera com ambos. O espírito humano fala como corporeidade e se desenvolve como corporeidade no entrelaçado 'corpo-espírito'.”.

Com o trajeto entre o nascimento e o aparecimento das primeiras palavras pode-se compreender o sentido existente no fenômeno da constituição do mundo e da absorção da língua no corpo infantil que se realiza a partir do aparente enfraquecimento do enlace existencial entre mãe e bebê. Com o fim do corpo-grávido no parto, o bebê tem na mãe o fundamento de suas vivências.

A ampliação do seu campo perceptivo pela melhoria e ordenação de seus sentidos incorpora os outros no seu mundo pessoal. O corpo como indica Merleau-Ponty é um sensível que também é fonte de significação, necessita sentir, afetar e ser afetado pelo outro. $\mathrm{O}$ bebê devora todos os outros que estão ao seu entorno como sentidos para si, também a mãe, base desse mundo em vias de estruturação e dessa maneira também a cultura e a língua (Merleau-Ponty, 2006b).

O infans desloca a mãe de sua posição de unidade de mundo para tê-la também como pessoa, para incorporar os outros que se assemelham a ela em seus gestos, absorve sua língua e seus gestos na relação vivida no mundo. Compreende-se, portanto, que a constituição do mundo 
da criança se dá pelo alargamento do seu enlace existencial com a mãe, cuja relação nutre de sentido todas as possibilidades de mundo, é ponto carnal do entrelaçamento da cultura e da segurança para a expressão de seus próprios sentidos.

\section{Considerações finais}

A constituição de mundo principia-se na vivência de existir do infans, uma modalidade existencial que carrega características próprias. Se inicialmente seu corpo não difere certos aspectos do real, esses são absorvidos conforme também se ampliam as possibilidades corpóreas de apropriação dada a maturação do ser. Uma sedimentação onde a natureza é apropriada pela potencia simbólica do corpo, embora se encontre sempre em relação a mesma natureza (Merleau-Ponty, 2006b). O corpo do infans realiza sua jornada de formação de mundo e compreende as verdades vividas no percebido. Seu saber é um conhecimento compartilhado com as vivencias com os outros.

O mundo descoberto carrega inúmeras perspectivas existentes na sociabilidade em que o infans está inserido. Ele é lançado em uma situação vivida e se apropria dela no seu curso de existir. A mãe forma-se no mesmo processo. A mulher lança-se na maternidade com os saberes de sua comunidade, mas é no enlace existencial com o bebê que a sedimentação de seus cuidados lhe propiciam também a segurança necessária - não a gênese da criança em seu corpo. O mundo vivido com a mãe é o mundo do infans, a boa maternagem é a fundação das possibilidades de um mundo melhor.

O surgimento da fala rende essa modalidade de existir os passos que agora são dados pelo corpo-puer, contudo o mundo vivido por ele sempre traz ecos das vivencias do infans. Mesmo noutras fases do existir, essas vivências constitutivas do infans marcam os passos do sujeito no mundo. Como diz Merleau-Ponty (2006b), embora exista separação racional e logica dos objetos, a afetiva não se realiza por completo. O enlace existencial mãe-bebê funda o mundo vivido da criança, mas progressivamente com a maturação e a inclusão de novas pessoas e narrativas no mundo a mãe afasta-se dessa posição de unicidade com a cultura para surgir como pessoa no mundo do filho. Contudo, o elo fundante se mantem, o mundo visto pela criança, em meio aos seus significados é sempre herdeiro daquele intimamente vivido com a mãe. Esse amor constituído ecoa como sentido por toda a vida.

\section{Referências bibliográficas}

Capalbo, C. (2008). Fenomenologia e ciências humanas. Aparecida, SP: Ideias \& Letras.

Crystal, D. (2007). How language works. New York, USA: Penguin Group.
Garc, E., \& Olaso, B. (1978). Dicionário de Filosofia. (A. J. Massano \& M. Palmerim, Trad). Lisboa, PT: Dom Quixote.

Husserl, E. (2008). A crise da humanidade europeia e a filosofia. (U. Zilles, Trad). Porto Alegre: EDIPUCRS. (Originalmente publicado em 1996)

Josgrilberg, R. S. (2015). Fenomenologia e educação. Em J. Lauand \& R. S. Josgrilberg, R. S. (Orgs.) Estudos em Antropologia, Religião e Educação (p. 7-25). São Paulo: Factasch Editora.

Josgrilberg, R. S. (2016). O corpo e seus desdobramentos interativos: os jogos de si mesmo como rejogo com os outros. Revista Internartional Studies on law and education, 23 (mai-ago), 13-24.

Landes, D. A. (2013). The Merleau-Ponty Dictionary. London, UK: Bloomsburry.

Le Breton, D. (2016). Antropologia dos sentidos. (F. Morás, Trad). Petrópolis, RJ: Vozes. (Originalmente publicado em 2006)

Merleau-Ponty, M. (1991). Signos. (M. E. G. Pereira, Trad). São Paulo: Martins Fontes. (Originalmente publicado em 1960)

Merleau-Ponty, M. (2006a). Fenomenologia da percepção. (C. A. R. de Moura, Trad). São Paulo: Martins Fontes. (Originalmente publicado em 1945)

Merleau-Ponty, M. (2006b). Psicologia e pedagogia da criança - Curso da Sorbonne 1949-1952. (I. Benedetti, Trad). São Paulo: Martins Fontes. (Originalmente publicado em 2001)

Nobrega, T.P.D. (2010). Uma fenomenologia do corpo. São Paulo: Livraria da Física.

Rocha, M. A. D. C. (1997). O falar como a expressão do ser na visão de Merleau-Ponty. Em M. A. V, Bicudo \& V. H. C. Espósito (Orgs), Joel Martins... um seminário avançado em fenomenologia (p. 97-111). São Paulo: EDUC.

Zilles, U. (2008). Introdução. Em Husserl, E. A crise da humanidade europeia e a filosofia (p. 7-57) (U. Zilles, Trad). Porto Alegre: EDIPUCRS. (originalmente publicado em 1996)

Fábio Luiz Socreppa da Fonseca - É mestrando em Educação (Universidade Metodista do Estado de São Paulo). Bolsista CAPES/PROSUP. Especialista em Psicopedagogia (PUC-SP), Aprimorado em Orientação em Queixa Escolar (USP), Graduado em Psicologia (Universidade Metodista do Estado de São Paulo. Membro do Grupo de Estudos da Fenomenologia das Idades da vida da UMESP. E-mail: fabio.socreppa.fonseca@gmail.com

Recebido em 30.03.17 Primeira Decisão Editorial em 22.06.17

Aceito em 21.07.17 